\title{
ON
}

\section{TREPHINING FOR TRAUMATIC EPILEPSY,}

\author{
WITH AN ILLUSTRATIVE CASE.
}

BY

\author{
JAMES F. WEST, F.R.C.S., \\ SENIOR SURGEON TO THE QUEEN'S HOSPITAL, BIRMINGHAM.
}

(Received October 14th-Read November 25th, 1879.)

The value of the operation of trephining has been, and still is, a vexed question in the surgical world ; at one time its merits have been extolled to the skies, at another the operation has been regarded as almost certainly fatal, and therefore only to be resorted to in very dangerous cases or where death would otherwise be inevitable. Between these extreme views the golden mean of practice will probably be found. The trephine is not to be used without good grounds for its employment, but in traumatic epilepsy and paralysis it has often proved of the greatest utility. With a view of helping to illustrate the treatment of epilepsy by the operation of trephining, I venture to bring forward this case, in which its good effects are certainly beyond dispute, the girl, from being in a state approaching coma and passing her urine and fæces involuntarily, having been restored to a state of comparative health; her speech and reason returned a few days after the trephine was 
used, and she has been rescued by means of the operation and the operation alone from idiocy, if not from death. I think, under these circumstances, I am fully justified in putting the case on record.

I thank your highly esteemed President personally for giving me the opportunity of bringing this subject before the Medical and Chirurgical Society, and I trust that in the discussion which will ensue, the opinions of many members who have given attention to this question, and who are far more entitled to speak on it than I am, may be elicited, and that thereby some of the difficulties in this branch of surgery may be cleared away.

Eleanor Holden, æt. 14, residing at 19, Belgrave Street, Birmingham was admitted into the Queen's Hospital on November 21st, 1878.

She was first placed under the care of Dr. Heslop, and then transferred for surgical treatment to $\mathrm{Mr}$. West's charge. During early childhood and until she was seven years old she was sharp and intelligent. She went to school and was able to read and write a little. In the spring of 1871, she was struck on the forehead by a stone, thrown by a boy in the street; she fell to the ground unconscious, but rallied in a few minutes, so as to be able to walk home. The mother described the wound as being "a hole so that you could see right into her head." She was attended to by a chemist, had no grave symptoms, and was considered to be quite well in three weeks. From the date of the accident the mother, however, noticed that she was drowsy, forgetful, less intelligent, and that she sooner grew tired than the other children. She frequently complained of "funny feelings in her head," which were worse after excitement, or after alcoholic stimulants. During the last three years, these phenomena have been more pronounced. She sometimes falls asleep over her food. During the current year she has had fits, which are described by her mother as follows :- "Suddenly she goes in a helpless way; she may be busying about; and instantly she seems 'to go bad;' she falls 
down gradually and gives a mournful cry, saying, ' Oh, my hand,' 'Oh, my arm;' sometimes one, sometimes the other." She complains most of the left side. Since the first of these epileptic fits she has been affected in her speech, sometimes entirely losing it, and she has passed her water involuntarily. She only vomited during the first attack, but never since. These fits occur paroxysmally, and they are becoming of more frequent occurrence, and longer in duration, and she now loses her speech for three or four days together; she has never had any hemiplegia or impairment of vision or hearing.

Present attack.-She had a fit four days before admission, and she has not spoken since. She has passed urine and fæces involuntarily, this being the first time of involuntary defecation. She is able to take nourishment.

Symptoms on admission.-Patient is small for her age; she has well-marked notches in her teeth; is fairly nourished ; is unable to stand ; she lies " all in a heap " in her mother's lap. Her expression is vacant and staringquite idiotic. Pupils somewhat dilated and possibly unequal; pulse 97 . She neither answers nor attempts to answer questions, nor will she open her mouth or protrude the tongue. There is twitching of the orbicularis oris muscle. There is no paralysis of the extremities present. A firm white cicatrix, as large as a fourpenny-piece, and depressed below the surface of the skin, to the extent of an eighth of an inch, is found upon the right side of the forehead, two inches above the eyebrow, and just to the right of the median line. All medical treatment having failed, and the patient's condition being apparently irremediable by other measures, $\mathrm{Mr}$. West determined to trephine, and the operation was performed on November 25th, 1878, as follows :-The patient having been anæsthetised by ether, a crucial incision extending down to the bone was made over the depressed cicatrix. $\mathrm{Mr}$. West then separated the pericranium with a raspatory, and having reflected the raised flaps removed with a small trephine two circles of bone, the one immediately 
over the depression in the outer table and the other a little to the right of and adjoining it. The former fragment showed that there had been depression of the outer table and compression of the diploë, although the inner table bore no evidence of having been fractured. The membranes were not injured in the operation, the spicula being washed away with a stream of tepid carbolised water. The pericranium was brought together by four catgut and the skin by four silver sutures. The operation was performed with antiseptic precautions, and dressed after Lister's method, except that no drainage tube was employed. The patient vomited immediately after the operation, but had no symptoms of any kind during the day. The pulse and temperature, which in the morning were $92^{\circ}$ and $97^{\circ}$ respectively, rose at night to $198^{\circ}$ and $98.5^{\circ}$.

25th.-She passed a comfortable night, and has no symptoms; she answers questions slightly; wound dressed; parts normal. Three sutures removed.

27th.- She had a good night, and is now able to answer questions readily. She has retained her urine and fæces since the operation; she protrudes the tongue when asked to do so.

28th.-She now can talk quite naturally; wound when dressed appeared solid, except at the upper part of the crucial incision. The remaining suture was removed.

30th.- She is quite intelligent. Bowels regular ; tongue moist and clean. The condition of the temperature and pulse from the date of the operation will be seen on examination of the accompanying chart.

December 3rd.-Antiseptics discontinued. On December 9th she sat up, and from that time till December 28th, when she left the hospital, she was walking about the wards, and was quite cheerful and happy. A gutta-percha cap, well padded and moulded to the shape of the head, was worn with comfort.

February 17th, 1879.-She was readmitted to-day, looking very poorly. She had been working very hard at home, and had been taken ill quite suddenly. By means 


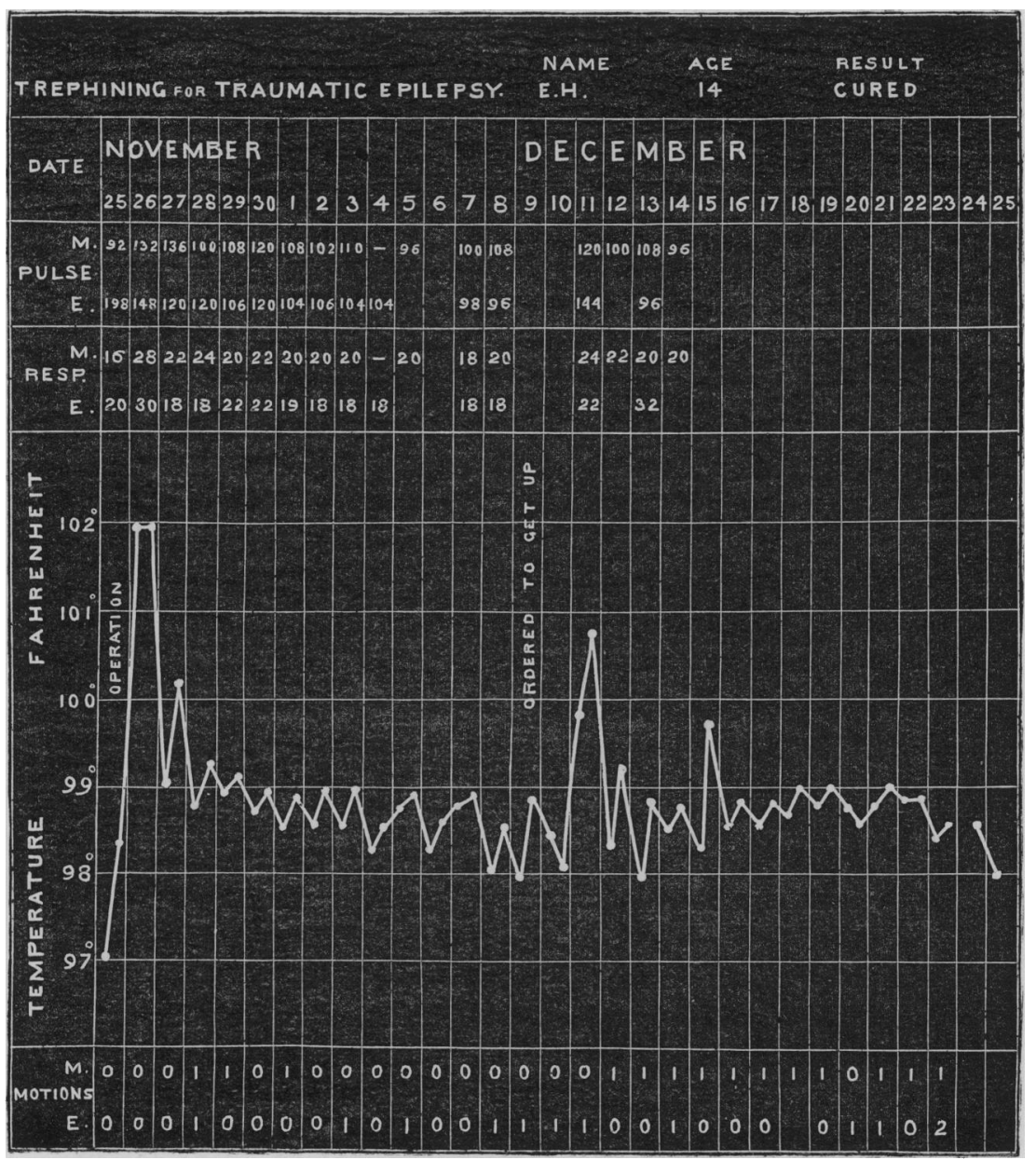


of free purgatives and absolute quiet she became quite intelligent again in ten or twelve days, and on March 17th she left the hospital as well as before, having had no epileptic attacks during her stay in the hospital.

May 5th, 1879.-She was readmitted with well-marked hemiplegia of the left side, but with no impairment of the intelligence; her speech was thick and her tongue, when protruded, turned to the left side; pupils equal.

Absolute quiet and purgatives put matters right in the course of ten days, so that no sign of paralysis remained.

On May 16th she was again able to go home. Since that time she has occasionally visited the hospital as an out-patient, but has never required to stay; she has taken iron and quinine, and has several times passed a few weeks in the country.

Her mental faculties have become more acute, and her temper better since the operation. She is, however soon tired, and requires great kindness and consideration from all those about her.

In bringing this case forward, I do not propose to go into the general question of the use of the trephine in injuries of the skull, but I intend to confine my observations as far as possible to those cases of epilepsy and paralysis in which it has been used, and from the consideration of recent writings on the subject to endeavour to show the value of the operation in certain suitable cases. I think it desirable to quote some authors and to give some statistics, but I trust I may be pardoned if I have omitted to mention many whose opinions are entitled to be heard, and that the omission may be attributed to my anxiety not to embarrass my paper with a too elaborate citation of authorities.

That epilepsy is not unfrequently due to injuries of the skull is abundantly proved in the history of surgery, but it is less widely known that relief of the symptoms has again and again followed the discharge of some portion of exfoliated bone, or the elevation of a portion of some of the cranial bones by the trephine. 
An interesting example of this disease where benefit was afforded by the keeping open an issue in the head, by which exfoliated fragments of the skull could be discharged, is given in Dr. Graves's ' Clinical Lectures,' p. 409.

Mr. South, in dealing with this subject, says ('Chelius's System of Surgery,' vol. i, p. 415) :-“ Trepanning may be necessary in continued severe headache with convulsions, or epileptic symptoms which decidedly arise from the place of the earlier injury," and he quotes four cases : two from the Museum of St. Thomas's Hospital, in which the operation was unsuccessful, and two from the practice of the elder Cline, in which trephining was followed by perfect recovery.

One of the most recondite and valuable memoirs in the English language, on 'Trephining for the Relief of Epileptiform Attacks occurring after Injury to the Head,' was written by my friend Dr. James Russell, Senior Physician of the Birmingham General Hospital, and appeared in the 'British Medical Journal' of 1865, and in it the whole subject is thoroughly discussed.

After giving the particulars of a case which occurred in his own practice, which was operated on by Mr. Bolton, and which unfortunately terminated unsuccessfully, he gives a resumé of 80 cases of epilepsy arising from injury, in 50 of which trephining was performed; of these, 44 recovered from the operation; progressive amendment and recovery ensued in all of them except in 5 cases. Speaking of the operation of trephining in epilepsy, Prof. Gross, in his ' System of Surgery' (vol. ii, p. 117) says, that the first case was by La Motte in 1795, and was partially successful; and he also mentions that in 1820 Dr. Dudley, in vol. $i$ of 'Transylvania Journal of Medicine,' published 5 cases, of which 3 were successful.

Prof. Gross has himself had 4 cases, 1 cure, and 3 deaths, while he has witnessed 3 others, which exded fatally. Dr. J. S. Billings ('Cincinnati Lancet,' June, 
1867) has given an analysis of 72 cases of epilepsy subjected to trephining, of which 42 were cured, 4 were unchanged, 16 proved fatal, and the rest were improved but not entirely relieved. In the 'Surg. Hist. of the War of the Rebellion," " 15 cases of gunshot fracture of skull are reported in which trephining was used, in which the patients recovered sufficiently to resume their duties and 4 sufficiently to return to modified duty, while in 6 the men recovered and were unchanged, paroled orfurloughed;" 35 recovered after trephining with different degrees of physical disability.

It is, however, only right to state, in contrast to these favorable results of operative treatment, that the most recent English statistics of trephining, as given by $\mathrm{Mr}$. Bryant in his 'Practice of Surgery' (vol. i, p. 232, 3rd edition, 1879) are not encouraging. He says : "At Guy's Hospital trephining and elevation of bone for head injuries have been performed in 51 cases during seven years, and of these only 12 recovered. At St. Bartholomew's Hospital it was recorded by Callender, in 1867, that the operation had not been performed for six years. At University College Erichsen gives 6 cases of recovery out of 17." On the other hand, the experience of the American Surgeons during the War of the Rebellion ('Surgical Hist.', table 8, vol. 1, p. 319) is far more satisfactory, 95 having recovered out of 220 cases, i.e. a rate of mortality of $56^{\circ} 6$; while Dr. Echeverria ('Archives de Médecine,' December, 1876) gives a table of 145 epileptics who were trephined, from which it appears that 93 were cured, 18 improved, 5 in which no change occurred, 1 aggravated, and 28 died-a mortality of $17 \cdot 5$ per cent.

Striking testimony to the value of the trephine in depressed fractures of the skull is given by Dr. Robert Hudson of Redruth ('British Medical Journal,' July 21st, 1877). No more enthusiastic admiration of the operation could be expressed than is given in his summary. "It is believed by those surgeons (i.e. in Redruth and Camborne) 
that no danger whatever attaches to the operation; and recovery is the rule after trephining operations." 1

The most valuable addition to our knowledge of this question is given in a recent French work, 'La Trépanation guidée par les localisations cérébrales,' by Dr. Le Just Championnière, Paris, 1878. In 1874 Dr. Le Just Championnière had under his care a man who was picked up insensible in the street with a superficial scalp wound over the left parietal eminence and some ecchymosis of the eyelids. He was found to have incomplete paralysis of the right upper limbs, and four days afterwards he was attacked with convulsions affecting the right shoulder and left arm, the lower limbs also being seat of regular spasms.

No improvement taking place and after due deliberation, Dr. Championnière explored the scalp wound, detected a fracture in the left parietal bone, and, to make a long story short, had the satisfaction of seeing his patient recover, not only from the epilepsy, but also from the paralysis; some aphasia, which persisted for a longer period, eventually disappeared. Dr. Championnière expresses the greatest faith in the operation of trephining, and asserts that it may be undertaken with a confidence formerly unknown, since the labours of Broca, Ferrier, Charcot, and others, have established the doctrine of cerebral localisation; "etant donnés certains troubles moteurs consecutifs à des traumatismes $d u$ crâne on peut determiner par leur observation assez nettement la region de l'écorce cérébrale

1 A case showing the good effects of the trephine in epilepsy, which was under the care of Mr. Cooper Forster and Dr. Wilks, is reported in the 'Lancet' for August 30th, 1873. The patient was a boatman, æt. 39, who suffered from epileptic fits produced by " a blow on the top of the head, which stunned him and produced a slight swelling" which remained four months after the accident. Iodide of potassium in large doses, and free incision down to the bone, which liberated a small quantity of pus, not having put a stop to the fits, Mr. Forster "trephined to the right of the median line and removed a piece of bone, which was rough and excavated on the outer surface, of great density of structure, and of increased thickness, being three eighths of an inch thick in one place and a quarter of an inch thick in another." There was not "the least sign of a fit" after the operation. 
compromisé, pour guider avec securité la main du chirurgien qui se propose de libérer par la trepanation du crâne."

Dr. Championnière gives to M. Broca the credit of being the first to initiate this method of trephining, guided by the phenomena of cerebral localisation. M. Broca's first case was unsuccessful, but in 1866 he brought before the Surgical Society of Paris the case of a child on whom the operation had been performed by him with perfect success for epileptiform convulsions coming on after fracture of the skull. In the discussion which followed M. Legouest, the eminent professor of military surgery, spoke in favour of the operation, and cited a case of fracture of the left parietal bone with paralysis of the right arm, in which a fatal result was in all probability avoided by the use of the trephine. He thus formulates his opinion of trephining in doubtful cases :- "Enfin pour exprimer toute ma pensée, je dirai, si singulière que puisse paraitre ma formule, qu'il y a probablement indication de trépaner toutes les fois qu'on doute qu'il y a lieu de le faire."

The subject of trephining has recently been the subject of important memoirs by MM. Larrey and Sédillot; the former, though not very strongly in favour of the operation, lays down a series of plain directions as to when and in what cases it should be done, and when it is contraindicated. These would be too lengthy to quote in full, but, as bearing on the subject of the trephine in epilepsy and paralysis, he recommends it " in cases where there are grave cerebral complications, prolonged hemiplegia with supposed extravasation, which have resisted all other methods of treatment." M. Sédillot, in a cornmunication to the Society of Medicine of Strasburg in 1869, expressed himself strongly in favour of trephining, and stated that now antiseptic treatment was employed the operation might be undertaken with far less risk than formerly, adding that, while at the Strasburg Hospital trephining had never before been successful, under the new method of procedure the operation had been followed by good 
results. In M. Sédillot's opinion as to the value of the antiseptic method of dressing after this operation I fully concur. In my case it answered admirably, the wound healing rapidly, and the patient being throughout entirely free from constitutional excitement, as is shown by reference to the accompanying temperature charts. In 1876, M. Sédillot again adrocated trephining in a paper presented to the Académie des Sciences, which contains the result of 106 observations made by him. In Germany trephining has not been a favourite operation; Stromeyer was strongly opposed to it, while Nussbaum, Esmarch, Beck, and Bergmann only perform it in exceptional cases, and their views may be taken as typical of the present state of opinion on this subject in the various schools of German surgery.

In France, on the other hand, trephining is becoming a popular operation, and one which daily seems to find fresh advocates.

The operation has been placed on a different basis since the existence of certain zones on the surface of the brain in the fronto-parietal region, which if irritated give rise to convulsive movements on the opposite side of the body, or if removed or destroyed, to paralysis of those parts, has been determined by the observations of Hitzig and Ferrier. It remained now only to determine what are the points on the surface of the skull which correspond with those parts of the brain. This difficult question Dr. Lucas Championnière proposes to solve by means of biauricular cartoons; he thinks it possible, by their means, to establish so correct a diagnosis of the site of the lesion that he could undertake the operation of trephining with precision in cases of paralysis of one set of muscles when other symptoms are absent, or where there are convulsions of the opposite half of the body to that which has been the seat of the injury.

The directions laid down by him, and by M. Broca, for finding the fissure of Rolando, around which most of the motor centres are situated, are very elaborate, and their voL. LXIII. 
enumeration would occupy too much time. Attention to them is no doubt of the highest importance to anyone called upon to diagnose the region of the brain which is the seat of injury. Further research in this direction will no doubt add largely to our knowledge of the indications which are to be derived from the theory of cerebral localisation. In the meantime we may be thankful to those, like Turner and Ferrier in this country, and Broca and Charcot in France, who have done so much for the department of physiological anatomy, denominated cranio-cerebral topography.

It seems to me in conclusion that in all cases of brain injury followed by epilepsy or paralysis which call for operative interference we have three great questions to determine :

1st. Is the theory of cerebral localisation sufficiently established to enable us to act upon it?

2nd. Are our indications in any given case, either of paralysis or epilepsy, sufficiently precise and well marked to warrant us in recommending the use of the trephine at a particular point of the skull?

3rd, and lastly, have we a better chance of serving our patient by immediate, by intermediary, or by secondary trephining.

The best answer I can give to these three questions may be thus summarised :

The first point must, I think, be conceded, after the recent experience of surgeons whom I have quoted both in France, Germany, and America.

The second point will be a long time before it is definitely settled, but cases such as those of Broca, Championnière, and the one recorded in this paper, gives us encouragement, and reference to them may aid us in determining to what part of the skull the trephine should be applied.

The third point must depend on the nature of the accident, and the extent of the lesion of the brain and its 
membranes, the constitution of, and the circumstances surrounding, the patient; but, as a general principle, it may be taken that secondary operations are less fatal than either primary or intermediary, and that when undertaken, the antiseptic treatment of the wound should always be employed. 